\title{
El Parque Natural Cabo de Gata-Níjar en Internet
}

Hoy en día existe una gran proliferación de páginas web de parques naturales en Internet lo que cada vez más nos hace reflexionar sobre el merecido protagonismo que están recobrando como elementos clave para la conservación de nuestro patrimonio natural y del medio ambiente. Considerar a los parques naturales como parte implicada de nuestro patrimonio más cercano comienza por concienciar al usuario de los elementos integradores de los mismos: flora, fauna, caserío, paisaje, etc. Un conjunto de piezas que por sí solas son elementos identificadores de una zona y que conjuntamente delimitan las características de un entorno en concreto.

Por ello, en las sedes web de los parques naturales existen numerosas entradas o botones que nos muestran todas las facetas culturales o naturales que conforman este espacio: pueblos que lo enmarcan, gastronomía y actividades culturales, rutas, paisajes, alojamientos, imágenes y oferta lúdica.

Este es el caso que analizaremos a continuación: la sede web del parque natural Cabo de Gata-Nijar.

Comenzamos la visita a la página principal con una presentación realizada en Macromedia Flash Player 5, donde de forma dinámica se proyecta un mensaje: "Espacios Naturales. Nunca verás nada igual. Cabogata.com".

En la parte superior de la página se aprecia una galería de 12 imágenes que se mantienen a lo largo de todo el recorrido como "leifmotiv" de la página web. Es una selección de fotografías que muestran diferentes aspectos del parque. Desde la playa de San José hasta el Faro de Cabo de Gata y la Iglesia de Las Salinas por poner un ejemplo.

En el lado izquierdo se encuentran los contenidos que podemos encontrar en la web y en el centro una fotografía aérea del entorno del parque. La página se cierra con otras dos fotografías en el lado derecho de una puesta de sol y del arrecife "Las Sirenas"

Pues bien, comenzando por la parte superior de la página nos centraremos en la galería de fotografías que se muestran como muestra de lo que se puede ver en el parque: Iglesia Las Salinas de Cabo de Gata, Vista del Faro de Cabo de Gata, Arrecife "Las Sirenas", Puesta de sol Almadraba, Pueblo de Las Salinas, Playa de San José, Playa de los Genoveses, Panorámica del faro, Charcas, Cala Blanca e isleta del Moro.

Si nos colocamos sobre cada una de las fotografías podemos acceder a una ampliación de las mismas con la opción de pasar a la siguiente y así hasta la última.

Ya en el lado izquierdo de la página aparecen los diversos contenidos de la página desplegados de forma vertical y con un efecto de resalte en negrilla y aumentado a la hora de situarse sobre cada uno de ellos.

El primero de todos se denomina "Parque Natural", y en él encontramos referencias sobre sus orígenes geográficos y su situación en la provincia de Almería, así como datos sobre su declaración como parque natural protegido y sobre las aves predominantes.

Este texto se encuadra en el centro de la página situándose la galería de imágenes antes descrita, pero de forma estática, a ambos lados del mismo.

El segundo apartado es el dedicado a "Las Playas", accediendo a una página donde se encuentran las doce fotografías en el centro y el listado de todas las playas del parque a ambos lado de la página.

Al acceder a una de ellas conectamos con un portal denominado Esplaya.com: el mundo de las playas en la red:

http://www.esplaya.com/mapa

En él aparece el mapa de Almería con las localidades más destacadas de su litoral y un menú desplegable con todas las playas que contiene. Si picamos sobre una de ellas se accede a una ficha de la playa elegida que sigue unos parámetros descriptivos comunes: Tipo de playa, Tamaño de la playa, Anchura media, Tipo de superficie, Oleaje y una Valoración de la misma sobre 100. Todo va acompañado de una o

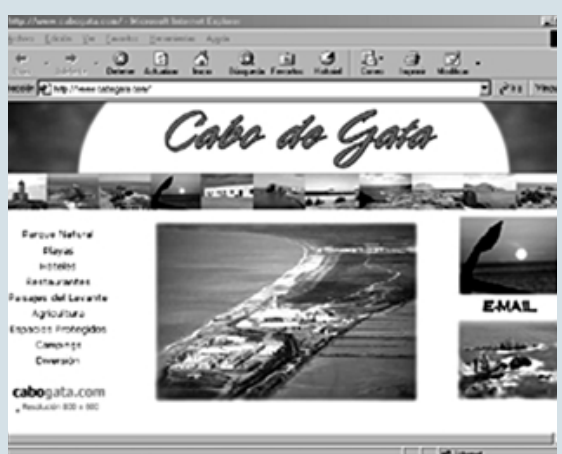

dos fotografías de la playa y de unos iconos en la parte superior derecha que nos indican si la playa está dotada de aparcamiento, duchas e instalaciones deportivas.

También hay que destacar dentro de la ficha un breve comentario sobre la playa bajo el título "Esplaya te cuenta"

El tercer apartado es el dedicado a "Hoteles", aunque de momento la página sólo nos muestra información sobre un único hotel de la zona, con una escueta referencia a algún otro establecimiento destacado. Aparece por tanto información sobre sus instalaciones, menús y especialidades, reservas, fotografías en movimiento y situación geográfica dentro de un mapa de Almería, así como datos de cómo llegar al lugar. La información se encuentra también disponible en inglés y en el margen izquierdo aparece de nuevo la galería de imágenes que acompaña siempre a toda la información de la página web. El apartado dedicado a "Restaurantes" vuelve a enlazar con la página del apartado anterior.

"Paisajes del Levante" conecta con una página dedicada a los paisajes de Almería en la que aparecen una selección de imágenes de la zona en el margen izquierdo que se amplían en el centro y con el autor de las mismas a pie de foto. Son un total de 43 imágenes albergadas en:

http://www.ual.es/ fguillen/paisajes/derechos.htm

"Agricultura" nos habla del origen histórico del cultivo del tomate que cuenta ya con una denominación de origen acuñada en la zona y extendida por la geografía española. 
El siguiente apartado resulta junto al de las playas el más interesante de toda la página web. Es el dedicado a "Espacios protegidos", y en él se conecta al igual que en algunos casos anteriores con una página web monográfica donde se recogen todos los espacios naturales de la provincia de Almería, que por sus excepcionales valores tienen un régimen especial de protección. Estos son: Cabo de Gata-Níjar, Sierra Nevada, Sierra María, Desierto de Tabernas, Karst en yesos Sorbas, Punta Entinas-Sabinar, La Albufera de Adra y Sierra Alhamilla.

Todos se encuentran resaltados con motas de color más intenso dentro del mapa de la provincia y están clasificados en tres categorías principales: parques naturales, parajes naturales y reservas naturales.

Todos ellos cuentan con una ficha individual a la que se accede desde un listado que se encuentra en el margen izquierdo de la página. La ficha muestra datos de la localización, tipo de paisaje, flora y fauna e itinerarios por el parque con algunas recomendaciones. Toda la información aparece acompañada de una o dos imágenes, y en algunos casos un icono nos muestra que podemos ver un video de la zona. En la parte superior y a través de otro icono accedemos a un listado de alojamientos del entorno descrito.

La dirección de la página es:

http://www.almeria-turismo.org/izquierda.htm

Los últimos apartados de la página son los que están dedicados a los Campings y a la oferta lúdica de la zona.

El apartado "Campings" enlaza con la página de la Asociación de Empresarios de Campings de Almería (AECA):

http://www.serinves.es/campings/default.htm

Encontramos en ella un mapa con todos los campings del parque situados en el mismo y si elegimos uno de ellos accedemos a una información más específica y amplia.

El apartado denominado "Diversión", nos muestra finalmente la amplia oferta de ocio y deporte que ofrece el parque. Entre ellas cabe destacar: deportes aéreos, deportes acuáticos, deportes de montaña, deportes de nieve, in door, otros, rutas, etc. Accediendo a cada uno de ellos encontramos una amplia galería de opciones con una fotografía representativa. Por ejemplo, si accedemos a deportes acuáticos, encontramos desde cómo explorar el fondo marino de sus costas a excursiones en Kayak, bodyboard y hockey subacuático, entre otros.

Esta página también conecta con otra dirección específica cuya reseña es:

http://www.tiramillas.net/antimuermo/acuaticos.html.

Como conclusión, cabe señalar la amplitud de matices informativos que puede llegar a albergar una sede web de estas características donde se presta especial interés por el paisaje y los espacios protegidos, sin abandonar, por otro lado, la importancia que cada vez más, hoy en día, está tomando la promoción turística y comercial de los mismos, en detrimento, en ocasiones, de su conservación y del respeto por su paisaje original.

La página se caracteriza por una amplia y variada oferta informativa, destacando la presencia de pocas páginas de elaboración propia y apostando por conectar con otras direcciones donde aparece una información en paralelo, elaborada de forma más monográfica y exhaustiva. Ello da una sensación de poca unidad y coherencia en el diseño, aunque el fin ultimo consistente en dar información práctica y útil al visitante ha sido bien resuelta.

La navegación es fácil puesto que el número de páginas existentes no es muy extenso, pero se echa de menos la permanencia del menú inicial en todas las páginas, lo que daría al conjunto mayor coherencia, dada la diversidad de autores implicados en el proyecto.

Finalmente, cabe deducir que por un lado, la información que más se demanda es el conocimiento del rutas y del entorno natural, pero que estos espacios son cada vez más conocidos y visitados, por lo que no cabe duda que también hay que valorar el aspecto lúdico y turístico que se oferta, sin abandonar nunca la conciencia cívica y protectora del entorno.
FICHA DE LA WEB URL PRINCIPAL

http://www.cabogata.com

\section{URLS SECUNDARIAS}

http://www.esplaya.com/mapa

http://www.ual.es/ fguillen/paisajes/derechos.htm http://www.almeria-turismo.org/izquierda.htm http://www.serinves.es/campings/default.htm http://www.tiramillas.net/antimuermo/acuaticos.html

TITULAR J.J. Gómez A. y otros enlaces INFORMACIÓN DISPONIBLE Aceptable CALIDAD GRÁFICA Buena DISEÑO WEB Medio FACILIDAD DE NAVEGACIÓN Aceptable VELOCIDAD DE CARGA Rápida ACTUALIZACIÓN No presenta fecha CALIDAD GLOBAL Aceptable

\section{Otros webs de interés sobre el Parque Natural Cabo de Gata-Níjar}

www.cabodegata-nijar.com

www.edisa.es/alpha

www.asemparna.com

www.parquenatural.com

www.tempranillo.es

www.bayyana.com

www.telebase.es/nijar

www.cma.junta-andalucia.es/espacios_naturales/ parques_naturales/pncabogata

www.lavozalmeria.net/lavozdigital/almeriax4/nijar.htm www.almeria-turismo.org

www.buceo.com

www.ocioymar.com

www.revistaiberica.com/iberica_natural/cabo_de _gata.htm 